\title{
Neovascular response in ischaemic central retinal vein occlusion after panretinal photocoagulation
}

\author{
I E Murdoch, P H Rosen, J S Shilling
}

\begin{abstract}
Twenty seven eyes treated for ischaemic central retinal vein occlusion with panretinal photocoagulation were reviewed. Prior to laser therapy anterior segment neovascularisation predominated (17 eyes) over posterior segment involvement ( 6 eyes). After photocoagulation anterior segment new vessels regressed or did not develop in the majority of cases. However, in five eyes previously absent posterior segment neovascularisation occurred. These results suggest that photocoagulation alters but does not eliminate retinal ischaemia, thus modulating the neovascular response.
\end{abstract}

Central retinal vein occlusion (CRVO) may have a devastating effect on vision and may result in chronic macular oedema and ocular neovascularisation, in particular rubeotic glaucoma. CRVOs with a relative absence of retinal ischaemia (about $75 \%$ of all CRVOs) have a better prognosis than those with retinal ischaemia (about $25 \%$ of all CRVOs). ${ }^{1}$ Panretinal photocoagulation (PRP) is now part of the accepted method of treatment for ischaemic CRVO. The aim of PRP is either to prevent neovascularisation or to induce regression of new vessels once they have occurred.

In contrast to the other vasoproliferative retinopathies - diabetic retinopathy, sickle cell retinopathy, and branch retinal vein occlusion where the emphasis of neovascularisation is in the posterior segment, in ischaemic CRVO the emphasis of new vessel formation is on the iris and in the drainage angle, with posterior segment involvement being less common. ${ }^{2-5}$ Previous studies have concentrated on the regression of neovascularisation following panretinal photocoagulation. ${ }^{6}$ However, some of our patients had received PRP for ischaemic CRVO and subsequently developed posterior segment neovascularisation. We therefore reviewed a series of eyes treated for ischaemic CRVO with PRP to determine the pattern of the ocular neovascular response in relation to the degree of ischaemia and photocoagulation.

\section{Materials and methods}

We reviewed all eyes treated at St Thomas's Hospital with PRP for ischaemic CRVO during 1980-7. Those without a proved diagnosis and those which had another vasoproliferative retinopathy were excluded from the study.

Twenty-seven eyes ( 11 right and 16 left) in 26 patients (12 males and 14 females) were included in our study. The mean period of follow-up was 30 months (range 3-93 months), and the average age of the patients was 72 years (range 47-84).
Twenty-two eyes had no other ocular disease. Of the remainder two had disciform macular degeneration, one ocular hypertension, one narrow drainage angles (treated with YAG iridotomies), and one Sjøgren's syndrome and early senile macular degeneration.

In all but five eyes prior to PRP the fundus lesions had been recorded by fundus photography and fluorescein angiography. In these five cases there was vitreous haemorrhage obscuring fundal details. Iris neovascularisation had been detected by observation of the iris and gonioscopy. The fluorescein angiograms were taken of the optic disc, posterior pole, and equatorial surveys. It was noted whether or not there was posterior segment neovascularisation, and the number of quadrants of retinal ischaemia were assessed from the amount of capillary nonperfusion.

Where no clinical review had been performed within the last three months the patients were recalled and repeat examinations performed, including repeat fundus photography and fluorescein angiography.

\section{Results}

Twenty one eyes had fluorescein angiography prior to PRP; 17 eyes had four quadrants of capillary closure and four eyes three or fewer. In the former group eight had rubeosis and four posterior segment new vessels, and in the latter group all eyes had rubeosis iridis with a mean interval between presumed onset and PRP of four months (range three-six months). Six did not have a fluorescein angiogram before photocoagulation, as it was thought to be unnecessary for treatment: five already had rubeosis iridis and one a vitreous haemorrhage.

The pattern of neovascularisation prior to PRP and on final review in each individual patient is shown in Table 1 together with the period from probable onset of CRVO to PRP. The presenting and final patterns of neovascularisation and the regression and formation of new vessels after PRP are shown in Table 2 . New vessels on the iris were present in 17 eyes at the time of PRP and new vessels on the disc or elsewhere in the retina in seven eyes. New vessels on the iris were successfully treated in 11 eyes and did not occur at any.stage in nine eyes (Table 1). There were five eyes (19-23, Table 1) in which new vessels on the iris were either absent or had resolved following photocoagulation but in which posterior segment new vessels subsequently developed.

New vessels on the iris were present when the time between the probable onset (when the patient first noticed visual loss) of the CRVO and PRP was shortest (four months), new vessels on 
Table 1 The pattern of neovascularisation and time from probable onset of CRVO to PRP

\begin{tabular}{|c|c|c|c|c|c|}
\hline \multirow[b]{2}{*}{ Number } & \multicolumn{2}{|c|}{ Posterior new vessels } & \multicolumn{2}{|c|}{$\begin{array}{l}\text { Anterior new } \\
\text { vessels }\end{array}$} & \multirow{2}{*}{$\begin{array}{l}\text { Time from probable } \\
\text { onset CRVO to PRP } \\
\text { (months) }\end{array}$} \\
\hline & Start & Finish & Start & Finish & \\
\hline 1 & No & No & No & No & 17 \\
\hline 2 & No & No & No & No & 5 \\
\hline 3 & No & No & Yes & No & 5 \\
\hline 4 & No & No & Yes & No & $2 \cdot 5$ \\
\hline 5 & No & No & Yes & No & 4 \\
\hline 6 & No & No & Yes & No & 3 \\
\hline 7 & No & No & Yes & No & 2 \\
\hline 8 & No & No & Yes & No & 1 \\
\hline 9 & No & No & Yes & No & 4 \\
\hline 10 & No & No & Yes & Yes & 2 \\
\hline 11 & No & No & Yes & Yes & 5 \\
\hline 12 & No & No & Yes & Yes & 8 \\
\hline 13 & No & No & Yes & Yes & 19 \\
\hline 14 & NVE & No & No & No & 11 \\
\hline 15 & NVE & No & No & No & 9 \\
\hline 16 & VH & No & No & No & 8 \\
\hline 17 & NVD/E & VH & No & No & 15 \\
\hline 18 & NVD & NVD & No & No & 18 \\
\hline 19 & No & NVE & No & No & 12 \\
\hline 20 & No & NVD & No & No & 1 \\
\hline 21 & & VH & Yes & No & 5 \\
\hline 22 & & NVE & Yes & No & 1 \\
\hline 23 & & NVD/E & Yes & No & \\
\hline 24 & NVD/E & NVE & Yes & No & $3 \cdot 5$ \\
\hline 25 & No & NVD & Yes & Yes & 3 \\
\hline 26 & No & VH & Yes & Yes & 2 \\
\hline 27 & No & VH & No & Yes & $2 \cdot 5$ \\
\hline
\end{tabular}

NVD $=$ new vessels on disc, $\mathrm{NVE}=$ elsewhere on retina $\mathrm{VH}=$ vitreous haemorrhage.

Table 2 Patterns of neovascularisation prior to, and net regression and formation of new vessels after PRP (number of eyes)

\begin{tabular}{lccll}
\hline New vessels & Pre-PRP & Post-PRP & $\begin{array}{l}\text { Vessels } \\
\text { regressed }\end{array}$ & $\begin{array}{l}\text { Vessels } \\
\text { formed }\end{array}$ \\
\hline NVD & 3 & $4(+1$ VH) & 1 & 3 \\
NVE & 4 & $4(+1$ VH) & 2 & 3 \\
NVI & 17 & 7 & 11 & 1 \\
VH & 1 & 4 & 1 & $3(+1$ NVD/E) \\
None & 5 & 12 & - & -
\end{tabular}

NVD $=$ new vessels on disc, $\mathrm{NVE}=$ elsewhere on retina, $\mathrm{NVI}=$ on iris, $\mathrm{VH}=$ vitreous haemorrhage.

the disc or elsewhere occurred when the time interval was the longest ( 12 months, Table 3 ).

Comparison of the laser therapy given to individual eyes for CRVO showed no significant difference between the number of burns administered to those with new vessels at the posterior pole after therapy (mean 2321 burns, standard deviation $(\mathrm{SD})=1502$ ) and those with no new vessels at the posterior pole after therapy (mean 1876 burns, $S D=700$ ). The number of laser sessions, power ranges used, spot sizes, and exposure times were similar in both groups.

Two eyes had supplementary therapy: number 4 had xenon arc photocoagulation (no neovascularisation on final review), and number 19 had cryotherapy (new vessels on the disc with vitreous haemorrhage and traction retinal detachment on final examination).

\section{Discussion}

The pattern of neovascular response prior to PRP is similar in our series to that previously reported $^{467}$ : a preponderance for involvement of the left eye is well recorded. ${ }^{38}$ None of our patients had concurrent primary glaucoma, and only one had ocular hypertension.

Our study has shown that the pattern of neovascularisation at the time of PRP can be related to the time from probable onset of CRVO to PRP (Table 3). Where rubeosis iridis occurred
Table 3 The pattern of new vessels at PRP and the time from probable onset of CRVO to PRP

\begin{tabular}{lc}
\hline $\begin{array}{l}\text { Pattern of new vessels } \\
\text { at } P R P\end{array}$ & $\begin{array}{c}\text { Average time from probable } \\
\text { onset of CRVO to PRP }\end{array}$ \\
\hline No NVI or NVD/E & 7.6 months $(5$ eyes) \\
NVD or NVE & 12 months $(5$ eyes) \\
NVI & 4.3 months $(16$ eyes) \\
NVI and NVD/E & 4 months $(1$ eye) \\
\hline
\end{tabular}

$\mathrm{NVD}=$ new vessels on disc, $\mathrm{NVE}=$ elsewhere on retina, $\mathrm{NVI}=$ on iris.

alone the average time from probable onset of CRVO to PRP was 4.3 months, the ' 100 -day glaucoma', and this occurred in 16 eyes (59\%). Where only posterior segment neovascularisation was present, the average time from CRVO onset to PRP was much longer (12 months). This was seen in only five eyes (19\%). Those eyes with no neovascular response at the time of laser therapy showed an intermediate time $(7 \cdot 6$ months) between probable onset of CRVO and PRP. This may suggest either that the stimulus to anterior segment neovascularisation, when present, is more intense than the stimulus to posterior segment neovascularisation or that the neovascular response of the anterior segment, once it is supplied with a hypoxic stimulus, is more rapid than that from the posterior segment. Finally it has been suggested that new vessels on the disc or elsewhere may indicate restoration of the retinal circulation ${ }^{9}$ with a concomitant reduction in the production of an 'angiogenic factor.' This may then be insufficient to stimulate new vessels on the iris. Overall PRP was effective in inducing regression of or prophylaxis against new vessels on the iris (Table 2) but not so effective for posterior segment new vessels.

The most interesting feature of our study is the five eyes in which rubeosis either had been absent or had resolved following photocoagulation but in which posterior segment new vessels subsequently developed, whether on the disc, or elsewhere in the retina, or as shown by the presence of vitreous haemorrhage. As the posterior segment neovascularisation occurred some time after PRP, it is unlikely that a postPRP inflammatory response was responsible for the appearance of new vessels on the disc or retina.

There is growing evidence that the neovascular response occurs due to an alteration induced by retinal hypoxia in the balance among proliferative and inhibitory growth factors produced by the retina and associated structures. ${ }^{210}$ "The original rationale for PRP was to reduce the amount of hypoxic retina and therefore reduce neovascularisation. More recent evidence suggests that photocoagulation alters the balance of the growth factors in favour of new vessel regression.

We propose a concept that, if an ischaemic CRVO occurs, the neovascular response of the affected eye varies according to the amount of hypoxic retina (Table 4), which can in turn be altered by PRP.

If hypoxia is severe, the eye responds by developing marked rubeosis iridis within three months - 100-day glaucoma. If the hypoxia is moderate then new vessels may develop on either the iris or at the posterior pole, but these occur 
Table 4 Degree of retinal ischaemia and the neovascular response

\begin{tabular}{|c|c|c|}
\hline Retinal ischaemia & Neovascular response & $\begin{array}{l}\text { Time } \\
\text { (months) }\end{array}$ \\
\hline $\begin{array}{l}\text { Severe ( }>3 \text { quadrants } \\
\text { Moderate (2-3 quadrants) } \\
\text { Mild (<1 quadrant) NVD/E }\end{array}$ & $\begin{array}{l}\text { Rubeotic glaucoma } \\
\text { NVD/E +/- NVI } \\
\text { NVD/E }\end{array}$ & $\begin{array}{l}<3 \\
=6 \\
>12\end{array}$ \\
\hline
\end{tabular}

Abbreviations as in Table 3.

later, at approximately six months after the vein occlusion. Finally, if the hypoxia, though present, is mild, then new vessels on the iris are very rare; new vessels, however, may develop at the posterior pole many months after the central retinal vein occlusion. Thus a severely ischaemic eye may be converted to a mildly ischaemic eye by PRP. This correlates with those eyes in this study with new vessels on the iris which subsequently developed new vessels elsewhere even after an 'adequate' PRP and resolution of the anterior segment neovascularisation. Therefore it is important that these patients should still remain under regular review.

The visual outcome following CRVO is generally poor, so that the usual aim of PRP is to convert a painful blind eye into a comfortable eye, but with poor visual potential. It has been said ${ }^{9}$ that if new vessels on the disc or retina occur the eye is saved, but if they occur on the iris then the eye is lost. Therefore converting an eye with new vessels on the iris to one with them on the disc or elsewhere on the retina may be an acceptable goal for PRP.

1 Hayreh SS. Classification of central retinal vein occlusion. Ophthalmology 1983; 90: 458-74.

2 Patz A. Clinical and experimental studies on retinal neovascularization. Am 7 Ophthalmol 1982; 94: 715-43.

3 Hayreh SS, Rojas P, Podhajsky P, Montague P, Woolson RF. Ocular neovascularization with retinal vein occlusion. Ophthalmology 1983; 90: 488-505.

4 Magargal LE, Donoso LA, Sanborn GE. Retinal ischaemia and risk of neovascularization following central retinal vein and risk of neovascularization following central
obstruction. Ophthalmology 1982; 89: 1241-5.

5 Chann CC, Little HL. Infrequency of retinal neovascularisation following central retinal vein occlusion. Ophthalmology 1979; 86: 256-62.

6 Laatikainen L, Kohner EM, Khoury D, Blach RK. Panretinal photocoagulation in central retinal vein occlusion: a randomised controlled study. $\mathrm{Br} \mathcal{F}$ Ophthalmol 1977; 61: 741-53.

7 Duke-Elder S. A system of ophthalmology. London: Kimpton, 1966; 10: 98-120.

8 Brown GC, Shah HG, Magargal LE, Savino PJ. Central retinal vein obstruction and carotid artery disease. Ophthalmology 1984; 91: 1627-33.

9 Smith RH. Thrombotic glaucoma: a clinico-pathological study. Int Ophthalmic Congr 1955; 2: 1164-75.

10 Boulton ME, McLeod D, Garner A. Vasoproliferative retinopathies: clinical, morphogenic and modulatory aspects. Eye 1988; 2 (suppl): S124-39.

11 Glaser B. Extracellular modulating factors and the control of intraocular neovascularisation. Arch Ophthalmol 1988; 106: 603-7. 